\title{
Suspended 3D pyrolytic carbon microelectrodes for electrochemistry
}

\author{
Hemanth, Suhith; Caviglia, Claudia; Keller, Stephan Sylvest
}

Published in:

Carbon

Link to article, DOI:

10.1016/j.carbon.2017.05.090

Publication date:

2017

Link back to DTU Orbit

Citation (APA):

Hemanth, S., Caviglia, C., \& Keller, S. S. (2017). Suspended 3D pyrolytic carbon microelectrodes for electrochemistry. Carbon, 121, 226-234. https://doi.org/10.1016/j.carbon.2017.05.090

\section{General rights}

Copyright and moral rights for the publications made accessible in the public portal are retained by the authors and/or other copyright owners and it is a condition of accessing publications that users recognise and abide by the legal requirements associated with these rights.

- Users may download and print one copy of any publication from the public portal for the purpose of private study or research.

- You may not further distribute the material or use it for any profit-making activity or commercial gain

- You may freely distribute the URL identifying the publication in the public portal

If you believe that this document breaches copyright please contact us providing details, and we will remove access to the work immediately and investigate your claim. 


\title{
Suspended 3D Pyrolytic Carbon Microelectrodes for Electrochemistry
}

\author{
Suhith Hemanth ${ }^{a^{*}}$, Claudia Caviglia ${ }^{a}$ and Stephan Sylvest Keller ${ }^{a}$ \\ ${ }^{a}$ Department of Micro- and Nanotechnology, DTU Nanotech, 2800 Kongens Lyngby, Denmark \\ suhem@nanotech.dtu.dk
}

\begin{abstract}
Carbon microelectrodes have a wide range of applications because of their unique material properties and biocompatibility. This work presents the fabrication and characterization of suspended pyrolytic carbon microstructures serving as three-dimensional (3D) carbon microelectrodes for electrochemical applications. A 3D polymer template in epoxy based photoresist (SU-8) was fabricated with multiple steps of UV photolithography and pyrolysed at $900{ }^{\circ} \mathrm{C}$ to obtain $3 D$ carbon microelectrodes. The pyrolytic carbon microstructures were characterized by SEM, Raman spectroscopy and XPS to determine the mechanical stability, shrinkage and material properties. The smallest feature size fabricated in the suspended carbon layer was $2 \mu \mathrm{m}$. A three electrode microelectrode chip with 3D pyrolytic carbon microstructures as the working electrode was designed and fabricated. The electrodes were characterized with cyclic voltammetry $(C V)$ and impedance spectroscopy (EIS) using potassium ferri-ferrocyanide redox probe in a custom made batch system with magnetic clamping. Different 3D pyrolytic carbon microelectrodes were compared and the optimal design displayed twice the peak current and half the charge transfer resistance as compared to $2 \mathrm{D}$ carbon electrodes. The higher sensitivity of $3 D$ carbon microelectrodes for electrochemical sensing was illustrated by dopamine detection.
\end{abstract}




\section{Introduction}

Advancements in the fabrication of 3D microelectrodes are of interest for numerous applications such as electrochemical sensors, energy storage devices and smart scaffolds for tissue engineering sensors [1][4]. The main advantage of 3D microelectrodes is that the larger electrode surface area potentially provides higher sensitivity for electrochemical sensing than the currently used 2D electrodes [5]. Furthermore, the 3D nature of the electrodes better mimics the natural environment of cells, which is relevant for applications in bioelectrochemistry or tissue engineering [6], [7]. Additionally to large surface area, optimal 3D microelectrodes should provide low resistivity, good structural and chemical stability, excellent reproducibility and low fabrication costs. Several processes have been proposed to fabricate 3D microelectrodes. With electroplating [8]-[10], injection molding [11], microsolidics [12] and screen printing [13] it can be difficult to control the feature size and/or a long and expensive process is required that may result in low-quality surfaces. Furthermore, the fabrication of structures with a highaspect ratio is difficult to achieve [1]. Additive manufacturing technologies such as 3D printing lack the resolution down to a few microns, which so far limits the fabrication to macroelectrodes [14]. Electrodeless electroplating is based on the use of a femtosecond laser and the writing is done in a serial way, leading to long processing times. Furthermore, this process results in a high surface roughness [15], [16]. Growth of carbon nanotubes requires highly controlled environments and fabrication of patterned high aspect ratio structures is challenging [17]. The combination of electroplating with sputtering and laser scribing is a complex process and also suffers from the above mentioned issues [18]. Regarding metal ion implantation, the process is based on the use of a shadow mask which limits the achievable resolution and density of the structures. Furthermore, one metal ion implantation step is only effective for a certain orientation and thus several steps are needed to obtain fully-coated 3D structures [19].

One of the most simple and cost-effective techniques for 3D microelectrode fabrication is carbon MEMS (C-MEMS). There, a patterned polymer template is treated at high $\left(\sim 1000{ }^{\circ} \mathrm{C}\right)$ temperatures in inert atmosphere ( $\mathrm{N}_{2}$ or $\mathrm{Ar}$ ) and transformed into a pyrolytic carbon electrode [20]. This process enables fabrication of 2D and 3D electrodes with the possibility for ad-hoc tailoring of designs to achieve unique sensitivities for specific applications. Additionally, carbon materials used as microelectrodes offer 
several attractive properties, such as wide electrochemical potential window, biocompatibility, chemical stability, and ease of functionalization [21]. These properties identify carbon as an ideal material for electrodes to be used as biosensors or in energy storage devices [7], [22], [23], [5].

In most C-MEMS processes, polymer templates have been fabricated using the chemically enhanced, negative tone epoxy photoresist (SU-8). SU-8 is composed of bisphenol-A novolac resin (EPON® SU8 resin, Shell Chemical Company, The Hague, The Netherlands) in an organic solvent, such as cyclopentanone or gamma-butyrolactone (GBL) and a photoinitiator usually being triarylsulfonium hexafluoroantimonate [24]. Fabrication techniques such as X-ray, e-beam and two-photon lithography have been employed for fabrication of 3D polymer templates for pyrolysis [25]-[27]. The limiting factor for these techniques is the low throughput as compared to standard UV photolithography. Different fabrication processes have been proposed to fabricate 3D SU-8 microstructures with UV photolithography e.g. using a polymerization stop layer SU-8 foil or highly optimized UV exposures at different wavelengths [28]-[30]. The complexity of the fabrication process increases as the structures become multilayered (i.e. more 3D). Furthermore, suspended SU-8 macrostructures have been fabricated with grayscale photolithography, but without achieving micron or submicron resolution [31].

Recently, we proposed a multi-step UV photolithography process followed by pyrolysis at $900{ }^{\circ} \mathrm{C}$ to obtain 3D carbon microelectrodes [32]. In this work, the optimized process was used to fabricate a three electrode microelectrode chip, with 3D carbon as the working electrode. The material properties of the pyrolytic carbon were analyzed with Raman spectroscopy and X-ray photoelectron spectroscopy (XPS). Mechanical stability and shrinkage of different designs of 3D carbon microelectrodes were characterized with optical microscopy and SEM. For electrochemical characterization cyclic voltammetry (CV) was conducted using potassium ferri-ferrocyanide as standard redox probe. The electron transfer on the optimal 3D microelectrode design was analyzed in detail using CV and electrochemical impedance spectroscopy (EIS). The results were compared to 2D microelectrodes (2D) and 2D microelectrodes with micropillars $\left(2 \mathrm{D}_{\mathrm{p}}\right)$. Finally, enhanced dopamine detection with square wave voltammetry (SWV) was demonstrated. 


\section{Experimental section}

\section{1. $\quad$ Microelectrode chips}

Three electrode microelectrode chips with overall dimensions of $1 \mathrm{~cm}$ x $3 \mathrm{~cm}$ were fabricated as shown in Figure 1. The microelectrode chips consists of pyrolytic carbon working (WE) and counter electrodes (CE). The circular working electrode has a diameter of $4 \mathrm{~mm}$. An Au pseudo reference electrode (RE) and contact pads are deposited by e-beam evaporation. The Au contact leads are passivated with SU-8 (Figure 1.K).

\subsection{Microfabrication of $3 D$ carbon microelectrodes}

The fabrication steps of the 3D carbon microelectrode chips are schematically described in Figure 1 (AJ). Figure 1.K shows the top view of a microelectrode chip with and without passivation layer (SU-8). The process is explained along cross-section AA (Figure 1.K). First, a $0.6 \mu \mathrm{m}$ thick $\mathrm{SiO}_{2}$ layer was deposited by thermally oxidation on a 4 -inch $\mathrm{Si}$ wafer (Figure 1.B). The $\mathrm{Si} / \mathrm{SiO}_{2}$ substrate was dehydrated in an oven at $250{ }^{\circ} \mathrm{C}$ for $2 \mathrm{~h}$ before spin coating the resist.

Approximately $5 \mathrm{ml}$ of negative photoresist (SU-8 2035 from MicroChem, USA) were manually dispensed on the 4-inch $\mathrm{Si} / \mathrm{SiO}_{2}$ substrate and spin coated (RCD8 T, Süss Micro-Tec, Germany) to deposit a $17 \mu \mathrm{m}$ thick layer (Figure 1.C). A soft-bake at $50{ }^{\circ} \mathrm{C}$ for 15 mins on a programmable hotplate (Harry Gestigkeit GmbH, Germany) was followed by a UV exposure step with an exposure dose, $\mathrm{D}_{1}=$ $210 \mathrm{mJcm}^{-2}$ in an EVG620 aligner (EVGroup, Austria) to define WE and CE (Figure 1.D). The aligner was equipped with a mercury lamp and a long pass filter (SU-8 filter), which was adjusted to a constant intensity of $7 \mathrm{mWcm}^{-2}$ at $365 \mathrm{~nm}$. This was followed by a post-exposure bake (PEB) at $50{ }^{\circ} \mathrm{C}$ for $1 \mathrm{~h}$. A second layer of SU-8 2075 was spin coated using a two-step process. A spread cycle of $30 \mathrm{~s}$ at $700 \mathrm{rpm}$ with 100 rpms $^{-1}$ acceleration was applied, followed by a thinning cycle at $2100 \mathrm{rpm}$ for $60 \mathrm{~s}$ with $500 \mathrm{rpms}^{-1}$ acceleration which yielded a $98 \mu \mathrm{m}$ thick film. The edge bead was removed by dispensing 
propylene glycol methyl ether acetate (PGMEA) at the edge of the rotating wafer (300 rpm) for $30 \mathrm{sec}$ resulting in a uniform SU-8 layer (Figure 1.E). A soft bake (SB) at $50^{\circ} \mathrm{C}$ for $6 \mathrm{~h}$ was followed by a twostep UV photolithography to achieve 3D suspended microstructures. The first exposure $\left(\mathrm{D}_{2}=\right.$ $147 \mathrm{mJcm}^{-2}$ ) defined the supporting pillars (Figure 1.F) and the partial exposure $\left(\mathrm{D}_{3}=28 \mathrm{mJcm}^{-2}\right)$ defined the suspended layer (Figure 1.G) [32]. This was followed by a PEB at $50^{\circ} \mathrm{C}$ for $8 \mathrm{~h}$. Development was performed in PGMEA in two steps of 10 min each, followed by isopropanol rinse for $30 \mathrm{~s}$ and drying in air (Figure 1.H). Next, an additional flood exposure with a total dose $\mathrm{D}=500 \mathrm{mJcm}^{-2}$ and a hard-bake at $90{ }^{\circ} \mathrm{C}$ for $15 \mathrm{~h}$ were performed. This procedure has earlier been used to minimize residual stress and enhance temporal stability of SU-8 due to improved crosslinking [33]. For analyzing the mechanical stability and shrinkage five different designs of 3D microelectrode were fabricated. The varied parameters were pillar diameter (d), pitch between the pillars ( $\phi)$, and diameter (w) and center-to-center distance (c) of the holes in the suspended layer.

The polymer (SU-8) templates were pyrolyzed in an ATV PEO604 furnace (ATV Tech., Germany) in inert atmosphere $\left(\mathrm{N}_{2}\right)$ in two steps, $200{ }^{\circ} \mathrm{C}$ for $30 \mathrm{~min}$ and $900{ }^{\circ} \mathrm{C}$ for $1 \mathrm{~h}$ with a ramp of $2{ }^{\circ} \mathrm{Cmin}^{-1}$ to produce 3D microelectrodes with suspended carbon (Figure 1.I) [34].

An Au pseudo-reference electrode and Au contact pads were deposited by e-beam evaporation through a shadow mask prepared using laser machining (Figure 1.J). For passivating the contact leads, a $6 \mu \mathrm{m}$ thick film of SU-8 2005 was spin coated and patterned as described above for the SU-8 2035 including the final flood exposure and hard bake.

For comparison of the electrochemical behavior, 2D microelectrode chips (Figure 1 without steps 1.E1.G) and 2D microelectrode chips with micropillars (Figure 1 without step 1.G) were fabricated with identical process parameters. 

A. Si substrate
B. Insulation layer
C. Spincoating SU-8
D. $1^{\text {st }}$ UV exposure

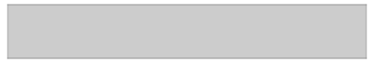

deposition

E. Spincoating Su-8

F. $2^{\text {nd }}$ UV exposure

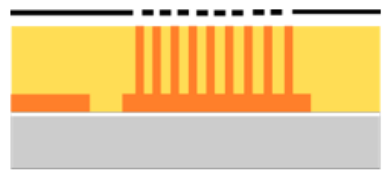

G. $3^{\text {rd }}$ UV exposure
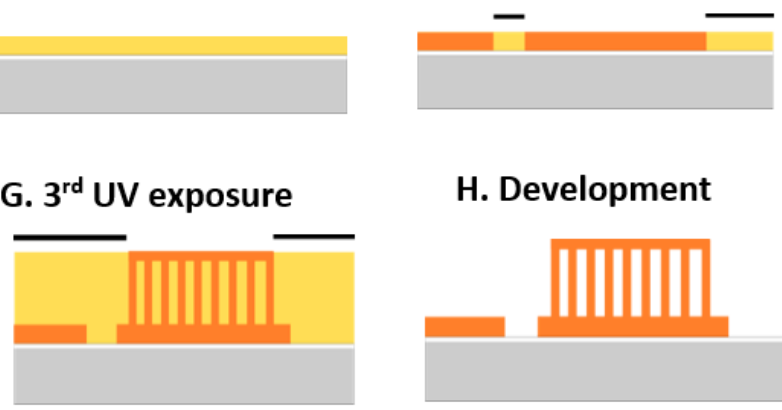

H. Development

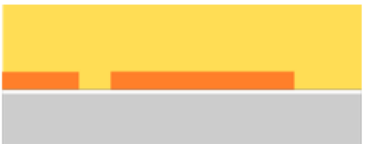

I. Pyrolysis

J. Au deposition
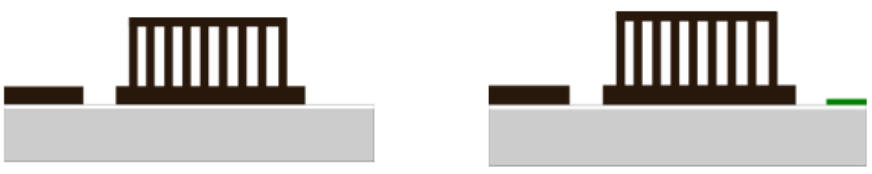

K. Microelectrode chips

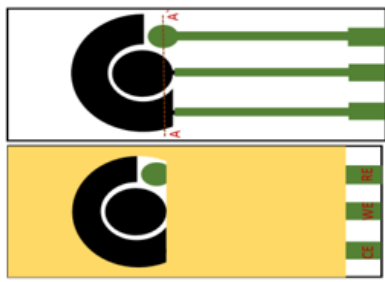

$\mathrm{Si}$

$\square \mathrm{SiO}_{2}$

SU-8

Exposed SU-8

Carbon

Gold

Mask

Figure 1 : Schematic of carbon microelectrode fabrication (A) Starting Si substrate (B) Thermal oxidation (C) SU-8 2035 is spin coated and soft baked (D) $1^{\text {st }} U$ V exposure and post exposure bake (E) Second layer SU-8 2075 is spin coated and baked (F) $2^{\text {nd }} U V$ exposure (G) short $3^{\text {rd }} U V$ exposure and post exposure bake (H) Development in PGMEA (I) Pyrolysis at $900{ }^{\circ} \mathrm{C}$ for $1 \mathrm{~h}$ (J) e-beam Au deposition through a shadow mask; (K) Top view of the microelectrode chip without and with passivation (SU-8 2005) layer

\subsection{Raman spectroscopy}

In order to evaluate the graphitization (i.e. disorder and crystallite) of the pyrolytic carbon 2D carbon films with a thickness of $2 \mu \mathrm{m}$ were fabricated with identical process parameters as described above. The samples were analyzed by visible Raman spectroscopy performed using a Raman microscope (Model DXR, Thermo Fisher Scientific Inc., Denmark) with an excitation wavelength of $532 \mathrm{~nm}$. All the spectra were recorded with a 10x long working distance objective and $10 \mathrm{~mW}$ laser power. The Raman spectra were analyzed using OMNIC software from Thermo Scientific. 


\subsection{X-ray photoelectron spectroscopy (XPS)}

The surface composition of pyrolytic carbon films was characterized using XPS. The analysis was carried out in a Thermo K-Alpha XPS instrument with a monochromatic Al-Ka-source. The binding energy survey from 0 to $1350 \mathrm{eV}$ was performed followed by spectral analysis in the $\mathrm{C}_{1 \mathrm{~s}}$ and $\mathrm{O}_{1 \mathrm{~s}}$ binding energy ranges. The atomic percentages of surface elements were extracted using the software package Avantage, provided by Thermo Fisher Scientific.

\subsection{Electrochemical characterization}

Prior to testing, the microelectrode chips (2D, 2Dp and 3D) were pretreated in $\mathrm{O}_{2}$ plasma (Electronic Diener, Germany) at $50 \mathrm{~W}$ for 65 seconds. CV and EIS were performed using $300 \mu \mathrm{L}$ potassium ferriferrocyanide $\left[\mathrm{Fe}(\mathrm{CN})_{6}\right]^{4-} /\left[\mathrm{Fe}(\mathrm{CN})_{6}\right]^{3-}$ redox probe in phosphate buffered saline (PBS). During the measurements the chips were allocated in self-aligning and magnetic clamping batch systems made of poly methyl methacrylate (PMMA) and pressure sensitive adhesive (PSA) as described in earlier work [32]. For every configuration analyzed, four chips from different fabrication batches were used. The different designs of 3D carbon microelectrodes were characterized using $\mathrm{CV}$ with $10 \mathrm{mM}\left[\mathrm{Fe}(\mathrm{CN})_{6}\right]^{4-} /$ $\left[\mathrm{Fe}(\mathrm{CN})_{6}\right]^{3-}$ solution. Cyclic voltammograms were acquired using a three-electrode configuration and a scan rate of $100 \mathrm{mVs}^{-1}$ in a potential range from $-600 \mathrm{mV}$ to $600 \mathrm{mV}$. The optimal 3D carbon microelectrode design was analyzed in detail with CV using different concentrations and scan rates and with EIS. EIS spectra were performed using a two-electrode configuration (WE and CE) in the frequency range of $0.1-10^{6} \mathrm{~Hz}$, applying a sinusoidal potential of $10 \mathrm{mV}$ and acquiring 10 points/decade. The frequency response was fitted with an equivalent circuit. The electrochemical behavior was compared to 2D and $2 \mathrm{D}_{\mathrm{p}}$ carbon microelectrodes. Square wave voltammetry (SWV) was performed on carbon electrodes for detection of different concentrations of dopamine hydrochloride (Sigma-Aldrich, USA). Measurements were acquired using a potentiostat (Autolab PGSTAT128N, Metronohm Autolab) and the software package NOVA was used to analyze the acquired data. 


\section{Results and discussion}

\subsection{D carbon microelectrode fabrication}

Different designs of 3D carbon microelectrodes were fabricated on the working electrode of a microelectrode chip. The 3D carbon microelectrodes consisted of three layers- a suspended grid layer, micropillars supporting the suspended structures and a planar base. Five different designs (design 1-5) of 3D carbon microelectrode with varying micropillars and suspended layers were fabricated to analyze their mechanical stability and the influence of the 3D geometry on the electrochemical performance. The nominal mask dimensions for the different designs and the final values measured after pyrolysis are summarized in Table 1. Figure 2.A-C shows three different polymer templates before pyrolysis of design 1, 3 and 5 respectively. An overview of the working electrode in the microelectrode chip is shown in Figure 2.D. Figure 2.E-I demonstrate that for all the five different 3D carbon microelectrode designs suspended microstructures were successfully fabricated. For the designs with $\Phi=\mathrm{c}$ (design 1,2 and 4) fabrication was very reproducible and resulted in regular suspended grids without defects. The minimal feature size of the suspended layer for these designs was around $7 \mu \mathrm{m}$ after pyrolysis. For designs 3 and 5 with $\Phi>$ c corresponding to multiple holes between micropillars the smallest feature size of the suspended layer was $2 \mu \mathrm{m}$. However, for those two designs fabrication was not reproducible and defects in the suspended layer were frequently observed. An observation for all designs are edge effects. The pillars at the edge of the electrode area are subjected to more stress which results in leaning towards the center.

Table 1: Nominal and actual dimensions for different 3D carbon microelectrode designs

\begin{tabular}{|c|c|c|c|c|c|c|c|}
\hline \multirow[t]{2}{*}{ Design } & \multicolumn{2}{|c|}{ Pillar diameter (d) } & \multirow{2}{*}{$\begin{array}{l}\text { Pillar pitch } \\
(\Phi)\end{array}$} & \multicolumn{2}{|c|}{ Hole diameter (w) } & \multirow{2}{*}{$\begin{array}{l}\text { Hole pitch } \\
\text { (c) }\end{array}$} & Unit cell \\
\hline & Nominal & Carbon & & Nominal & Carbon & & \\
\hline Design 1 & $10 \mu \mathrm{m}$ & $6.7 \mu \mathrm{m}$ & $50 \mu \mathrm{m}$ & $25 \mu \mathrm{m}$ & $29 \mu \mathrm{m}$ & $50 \mu \mathrm{m}$ & \\
\hline Design 2 & $20 \mu \mathrm{m}$ & $12 \mu \mathrm{m}$ & $50 \mu \mathrm{m}$ & $25 \mu \mathrm{m}$ & $29 \mu \mathrm{m}$ & $50 \mu \mathrm{m}$ & \\
\hline Design 3 & $20 \mu \mathrm{m}$ & $12 \mu \mathrm{m}$ & $75 \mu \mathrm{m}$ & $10 \mu \mathrm{m}$ & $14 \mu \mathrm{m}$ & $20 \mu \mathrm{m}$ & \\
\hline Design 4 & $50 \mu \mathrm{m}$ & $30 \mu \mathrm{m}$ & $100 \mu \mathrm{m}$ & $50 \mu \mathrm{m}$ & $63 \mu \mathrm{m}$ & $100 \mu \mathrm{m}$ & \\
\hline Design 5 & $50 \mu \mathrm{m}$ & $30 \mu \mathrm{m}$ & $100 \mu \mathrm{m}$ & $10 \mu \mathrm{m}$ & $14 \mu \mathrm{m}$ & $20 \mu \mathrm{m}$ & $\Phi$ \\
\hline
\end{tabular}



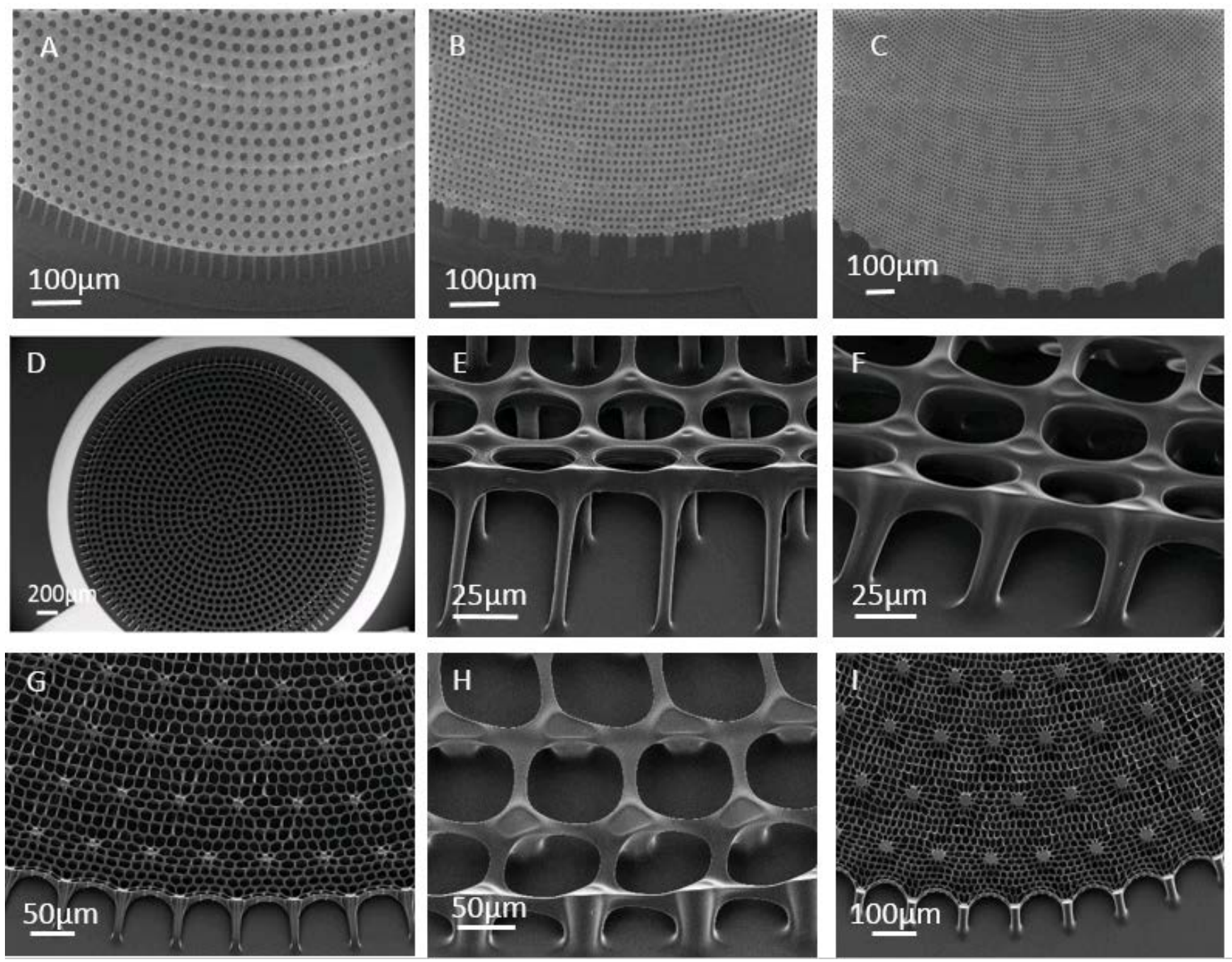

Figure 2 : (A)-(C) SU-8 polymer templates of designs 1,3 and 5 respectively ; (D) Overview of working electrode of microelectrode chip with 3D carbon (design 1); (E) - (I) Different 3D carbon microelectrodes with designs 1-5

\subsection{D carbon shrinkage analysis}

One of the major challenges in 3D microelectrode fabrication with the proposed process was the shrinkage during the pyrolysis. High shrinkage results in higher residual stress, which in turn can results in deformation, delamination and collapse of 3D microstructures. The values of nominal and actual pillar diameters and hole sizes reported in Table 1 demonstrate that considerable shrinkage was observed for all 3D microelectrode designs. 
Figure 3.A and B shows an example of a SU-8 template and the corresponding carbon structures, respectively. We investigated the vertical and lateral shrinkage of the pillars and vertical shrinkage of the suspended structures by SEM imaging before and after pyrolysis. The \% shrinkage $S$ was expressed as [35]:

$$
S=1-\frac{\text { Carbon }}{S U-8}
$$

Where "SU-8" is a dimensional parameter of the SU-8 microstructure before pyrolysis such as the height, pillar diameter or suspended layer thickness and "carbon" is the dimension of the corresponding carbon microstructure after pyrolysis. The total height (h), pillar diameter (d) and suspended layer thickness decreased by $48.3 \%, 41.0 \%$ and $48.4 \%$ respectively. The percentage of shrinkage is comparable to reported values for pyrolysis of SU-8 [36], [37]. The large shrinkage occurs due to multiple concurrent reactions happening during pyrolysis which include dehydrogenation, cyclization, condensation, hydrogen transfer and isomerization [38], [39]. Figure 2 demonstrates that despite the large shrinkage all 3D microelectrode designs were structurally intact after fabrication. However, the defects observed for design 3 and 5 were probably a result of the residual stress due to shrinkage.
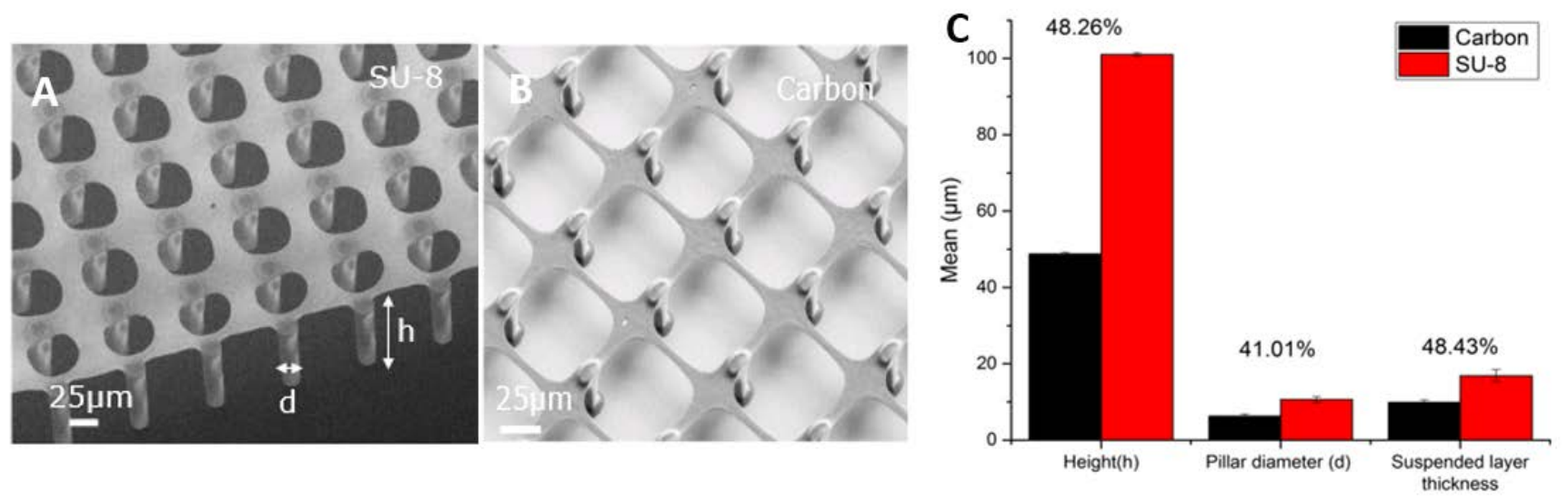

Figure 3: (A) SU-8 polymer microstructure template, (B) Corresponding carbon microstructures and

(C) Percentage shrinkage analysis for design 1 


\subsection{Raman spectroscopy and XPS}

Raman spectroscopy provides information about the degree of disorder of pyrolytic carbon. In pyrolytic carbon, the E2g vibrational mode at $1580 \mathrm{~cm}^{-1}$ (also present in graphite) and the A1g vibrational mode at $1360 \mathrm{~cm}^{-1}$ are Raman active [40]. The E2g mode results in a peak in the Raman spectrum, called " $\mathrm{G}$ " peak, where G stands for "graphite”. The G peak is caused by bond stretching of all sp2 hybridized C atoms in rings as well as in chains. When the symmetry in the graphite lattice is broken due to presence of disordered regions, the $A_{1 g}$ mode becomes active. This results in a new peak near $1360 \mathrm{~cm}^{-1}$, called the "D” peak where D stands for disordered [41]. Figure 4.A shows the Raman spectra of pyrolytic carbon derived from SU-8 photoresist where both D and G peaks are identified, which means that both amorphous and graphitic regions are present as reported previously for pyrolytic carbon [42]. Here, the observed upshift of the $\mathrm{G}$ peak to $1596 \mathrm{~cm}^{-1}$ is probably due to the presence of disordered graphite [43]

XPS survey spectra were used to evaluate the atomic percentage composition of pyrolytic carbon derived from SU-8 polymer precursors. The analysis showed carbon $\left(\mathrm{C}_{1 \mathrm{~s}}\right)$ and oxygen $\left(\mathrm{O}_{1 \mathrm{~s}}\right)$ peaks between 280 $-290 \mathrm{eV}$ and 525 - $540 \mathrm{eV}$ respectively (Figure 4.B) which is in accordance with previously reported results for pyrolytic carbon [42]. The carbon microelectrode consists of $94.3 \%$ of carbon and $5.7 \%$ oxygen.
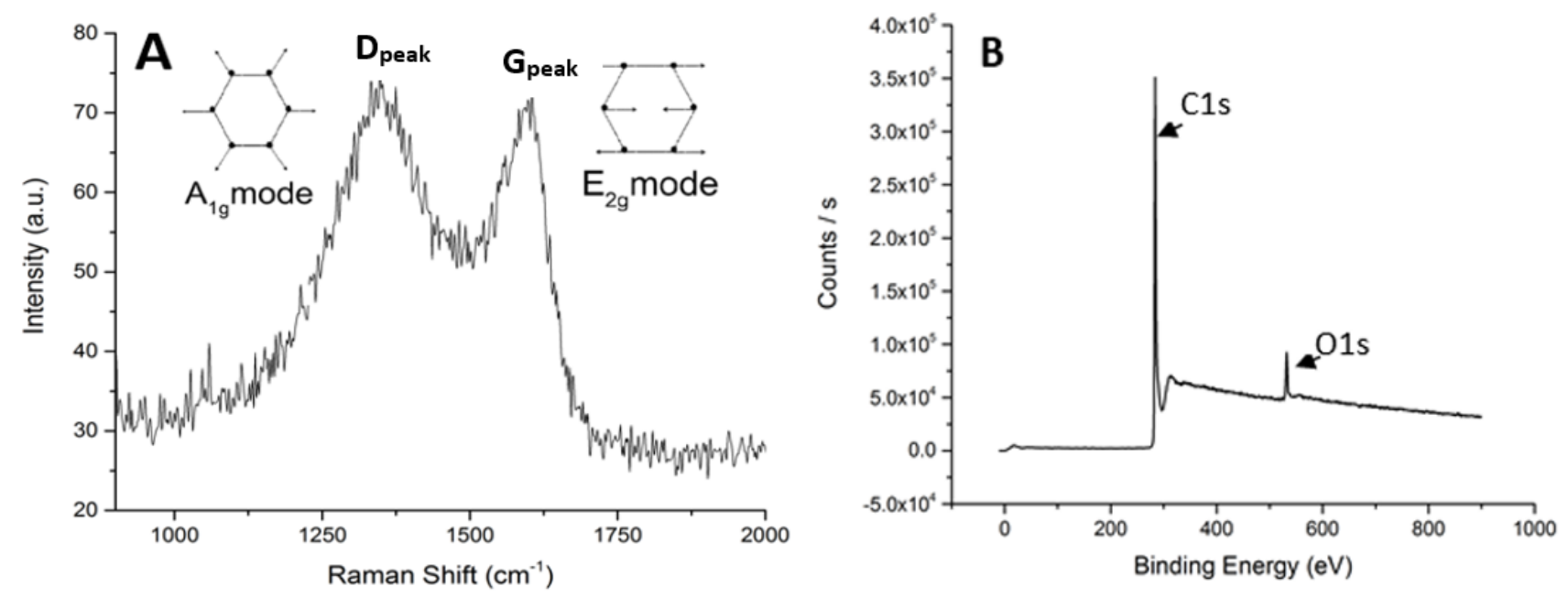

Figure 4: (a) Raman and (b) XPS spectra of carbon microelectrode 


\subsection{Cyclic voltammetry (CV)}

CV was performed on all five designs of 3D carbon microelectrodes (Table 1 and Figure 5). For each design, four chips of from different fabrication batches were characterized using $10 \mathrm{mM}$ potassium ferriferrocyanide as redox probe. Figure 5.A shows representative CVs for 3D carbon microelectrodes recorded with design 1, 2 and 4 which displayed reproducible electrochemical behavior.

Figure 5.B summarizes the mean anodic peak current $\mathrm{I}_{\mathrm{a}}$ of different designs ( $\mathrm{N}=4$ chips) along with their respective estimated surface area (calculation see supplementary information S1). All 3D microelectrode designs displayed higher peak currents than the 2D microelectrode. The recorded peak current increased for 3D microelectrodes with an increase in estimated surface area. In a reversible redox system, the peak current is directly proportional to the electron transfer on the surface [44]. This is well reflected in the experiments, where for example the 3D microelectrode design 1 with surface area $21.2 \mathrm{~mm}^{2}$ gives a peak current $\mathrm{I}_{\mathrm{a}}=0.61 \mathrm{~mA}$ which is a twofold higher signal compared to the $2 \mathrm{D}$ electrode with $\mathrm{I}_{\mathrm{a}}=0.32 \mathrm{~mA}$ for a surface area of $12.6 \mathrm{~mm}^{2}$. The current density obtained by normalization with the estimated surface area was $0.25 \mathrm{~mA} \mathrm{~cm}{ }^{-2}$ for $2 \mathrm{D}, 0.28 \mathrm{~mA} \mathrm{~cm}^{-2}$ for design $1,0.24 \mathrm{~mA} \mathrm{~cm}^{-2}$ for design 2 and $0.28 \mathrm{~mA} \mathrm{~cm}^{-2}$ for design 4. The comparable values 2D and 3D electrodes indicate that all parts of the 3D carbon microelectrodes are electrically connected and able to contribute to the electron transfer at the WE.
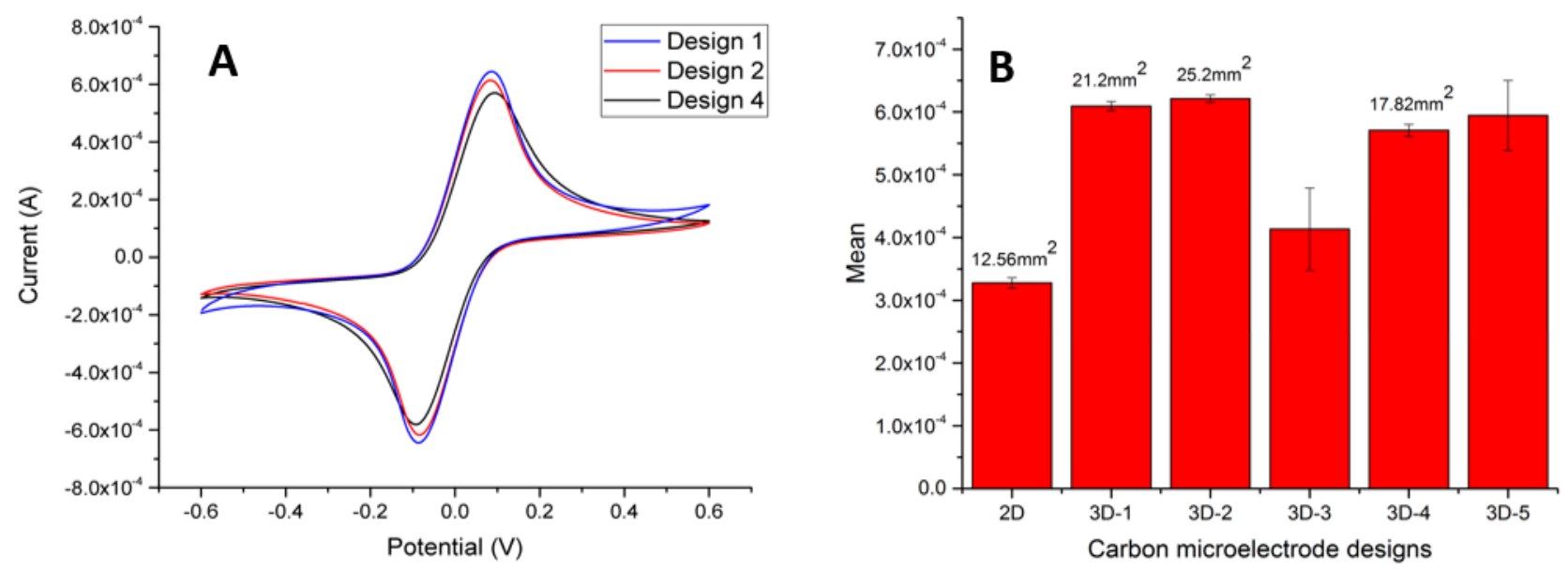
Figure 5: (A) CV of 2D and different 3D carbon microelectrode designs (1, 2 and 4) (B) anodic peak current with standard deviations for 2D and 3D microelectrodes ( $\mathrm{N}-4$ chips)

For design 3 and 5 lack of reproducibility was observed for the electrochemical measurements, which was reflected in the higher standard deviation of the measured peak current in Figure 5.B. This is attributed to the defects and irregularities of the suspended carbon layer observed by SEM as discussed earlier. Furthermore, calculation of the surface area for these two designs was very difficult due to the small features in the suspended carbon layers.

Design 1 was selected for further detailed electrochemical analysis, since it had the smallest pillar dimensions with high redox peak currents and was also highly reproducible. In all the following experiments, this optimal 3D carbon microelectrode was compared with planar carbon microelectrodes (2D) and 2D microelectrodes with micropillars on top (2Dp). These three different microelectrodes (2D, 2D and 3D) are shown in Figure 6.A-E. CV was carried out with $10 \mathrm{mM}$ potassium ferri-ferrocyanide redox probes. Figure 6.F shows that the 3D microelectrodes provided a higher peak current and a lower potential difference $\left(\Delta \mathrm{E}_{\mathrm{p}}\right)$. The peak current is directly proportional to the electron transfer on the electrode surface, which is higher for 3D microelectrodes $\left(\mathrm{I}_{\mathrm{a}}=0.58 \pm 0.008 \mathrm{~mA}\right)$ as compared to $2 \mathrm{D}\left(\mathrm{I}_{a}\right.$ $=0.29 \pm 0.01 \mathrm{~mA})$ or $2 \mathrm{D}_{\mathrm{p}}(0.42 \pm 0.004 \mathrm{~mA})$ microelectrode. $\Delta \mathrm{E}_{\mathrm{p}}$ is mainly influenced by diffusion rates of the analyte, which is $59 \mathrm{mV}$ for an ideal case but generally is higher for practical applications. Hence 3D carbon microelectrodes with a smaller $\Delta \mathrm{E}_{\mathrm{p}}=210 \mathrm{mV}$ has a higher diffusion as compared to $2 \mathrm{D}$ electrode $\Delta \mathrm{E}_{\mathrm{p}}=295 \mathrm{mV}$. 

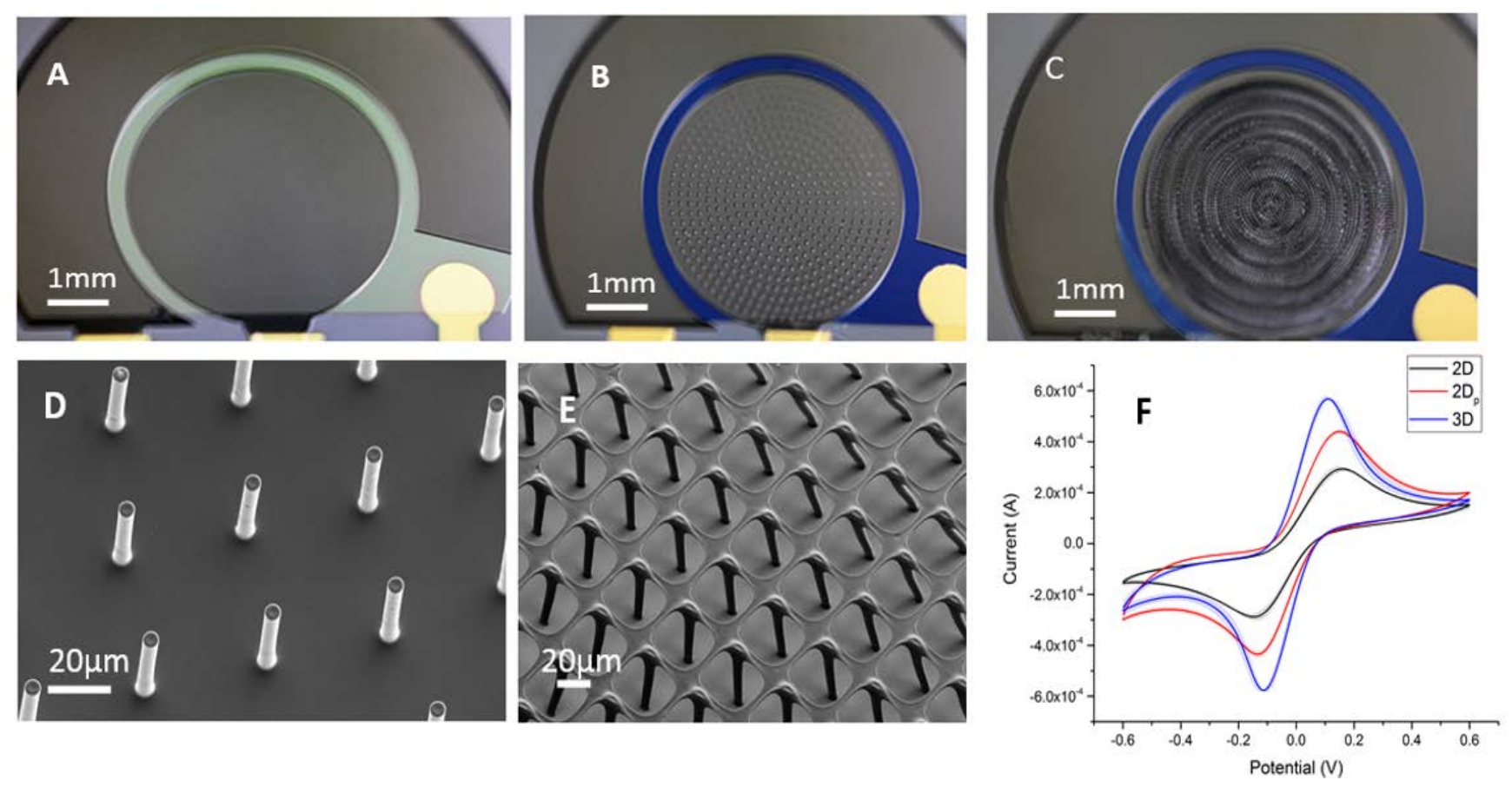

Figure 6: (A- B) Carbon microelectrodes : A- 2D, B- 2D and C- 3D (design 1), (D-E) SEM image of working electrode of $2 \mathrm{D}_{\mathrm{p}}$ and $3 \mathrm{D}$, (F) CV with $10 \mathrm{mM} \mathrm{Fe}(\mathrm{CN}) 6^{3-/ 4-}(\mathrm{N}=4$ chips)

The reversibility of the electron transfer for the 2D, 2Dp and 3D carbon microelectrodes was analyzed by $\mathrm{CV}$ at different scan rates with a constant concentration of $10 \mathrm{mM}$ potassium ferri-ferrocyanide redox probes. Figure 7.A shows representative cyclic voltammograms recorded for 3D carbon microelectrodes at different scan rates. Figure 7.B demonstrates that the peak currents are directly proportional to the square root of the scan rate, which is the case for reversible systems as described by the Randles-Sevcik equation [44]. CV's at different scan rates for $2 \mathrm{D}$ and $2 \mathrm{D}_{\mathrm{p}}$ electrodes are given in supplementary information S2. 3D carbon microelectrodes showed a higher electron transfer as compared to 2D and $2 \mathrm{D}_{\mathrm{p}}$ (Figure 7.B). The $\Delta \mathrm{E}_{\mathrm{p}}$ was found to be constant at different scan rates, as it is the case for a stable diffusion controlled reversible reaction system. 

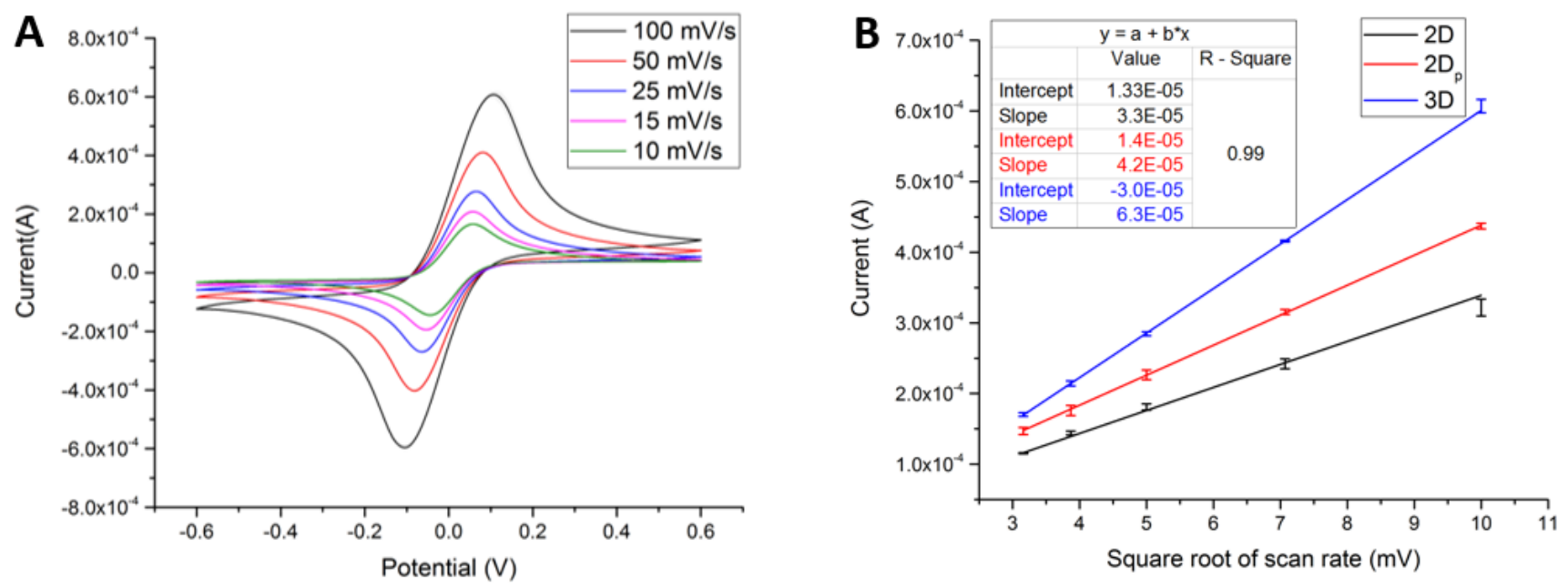

Figure 7: (A) 3D microelectrode CV with different scan rates (B) Average with standard deviation of peak currents as a linear relation of square root of scan rates $(\mathrm{N}=4)$

The 2D, 2Dp and 3D carbon microelectrodes were also characterized for different concentrations (1.25 mM, $2.5 \mathrm{mM}, 5 \mathrm{mM}, 10 \mathrm{mM}, 15 \mathrm{mM}$ and $20 \mathrm{mM}$ ) of potassium ferri-ferrocyanide redox probes at a constant scan rate of $100 \mathrm{mVs}^{-1}$. Figure 8.A shows representative cyclic voltammograms of 3D carbon microelectrodes with different concentration of $\mathrm{Fe}(\mathrm{CN}) 6^{3-/ 4-}$. Figure 8.B demonstrates that the peak current increases linearly with an increase in concentration as described by the Randles-Sevcik equation [44]. CV's with different concentrations of the redox probe for $2 \mathrm{D}$ and $2 \mathrm{D}_{\mathrm{p}}$ electrodes are given in supplementary information S3. Also in this case, the $\Delta \mathrm{E}_{\mathrm{p}}$ was found to be constant for a given configuration. The electrochemical characterisation showed that the electrode reaction was diffusion controlled. The electron transfer (peak current) was found to be higher (2 folds) for 3D microelectrodes when compared to $2 \mathrm{D}$ for all concentrations.

The sensitivity of the 3D carbon microelectrodes was $56.2 \mu \mathrm{A} \mathrm{mM}^{-1}$ (slope of the fitting in Figure 8.B) and $4.5 \mu \mathrm{A} \mathrm{mM}^{-1} \mathrm{~mm}^{-2}$ (considering WE footprint area $=12.56 \mathrm{~mm}^{2}$ ), which is higher than the reported values for unmodified carbon microelectrodes [43], [45]-[47]. The higher sensitivity is due the increase in the surface area of the working electrode. The sensitivity of $2 \mathrm{D}$ and $2 \mathrm{D}_{\mathrm{p}}$ chips are $25.5 \mu \mathrm{A} \mathrm{mM}{ }^{-1}$ and $41.3 \mu \mathrm{A} \mathrm{mM}{ }^{-1}$ respectively. 

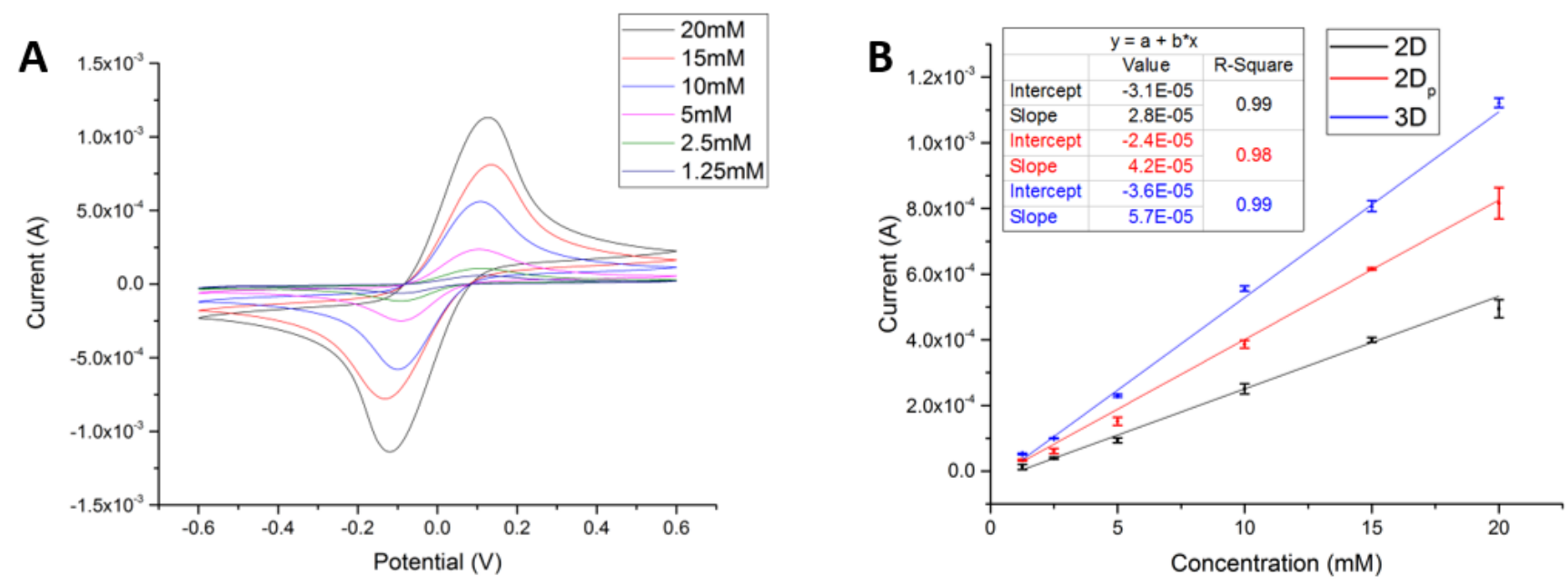

Figure 8: (A) CV of 3D carbon microelectrode with different concentration of $\mathrm{Fe}(\mathrm{CN}) 6^{3-/ 4-}$ concentrations (B) Average of peak currents with standard deviation at different concentrations of $\mathrm{Fe}(\mathrm{CN}) 6^{3-/ 4-}(\mathrm{N}=4)$

\subsection{Electrochemical impedance spectroscopy (EIS)}

EIS allows for further characterization of the carbon microelectrodes and it is a useful tool to understand the properties of an entire electrochemical set-up including electrode material properties and external interfacing instrumentations [48]. Based on the results obtained with EIS an equivalent circuit for the electrode can be determined, which clearly illustrates the device properties. Figure 9.A shows the Nyquist plot for 2D, 2 $\mathrm{D}_{\mathrm{p}}$ and 3D carbon microelectrode with the standard deviation ( $\mathrm{N}=4$ chips). An equivalent circuit, derived from a modified Randels model [36], was used to fit the impedance spectra obtained with different electrode configurations. Figure 9.B shows the equivalent circuit used (inset) and the fitting for a representative Nyquist plot of a 3D carbon microelectrode. The bulk carbon electrode material can be modeled by a series of capacitances $\left(\mathrm{C}_{B}\right)$ and resistances $\left(\mathrm{R}_{B}\right)$ in parallel or an equivalent $\mathrm{R}_{B}$ and $\mathrm{C}_{B}$ [36]. The resistance of the electrolyte and the charge transfer at the electrode surface can be represented by resistances Rs and $R_{c t}$, respectively, as shown in Figure 9.B.

Table 2 summarizes the values of equivalent circuit components extracted from the fitting of the experimental data where $Q$ is the constant phase element (CPE) at a frequency $\omega-1, \alpha$ is the multiplication factor of the phase angle and $\mathrm{W}$ is the Warburg impedance. 

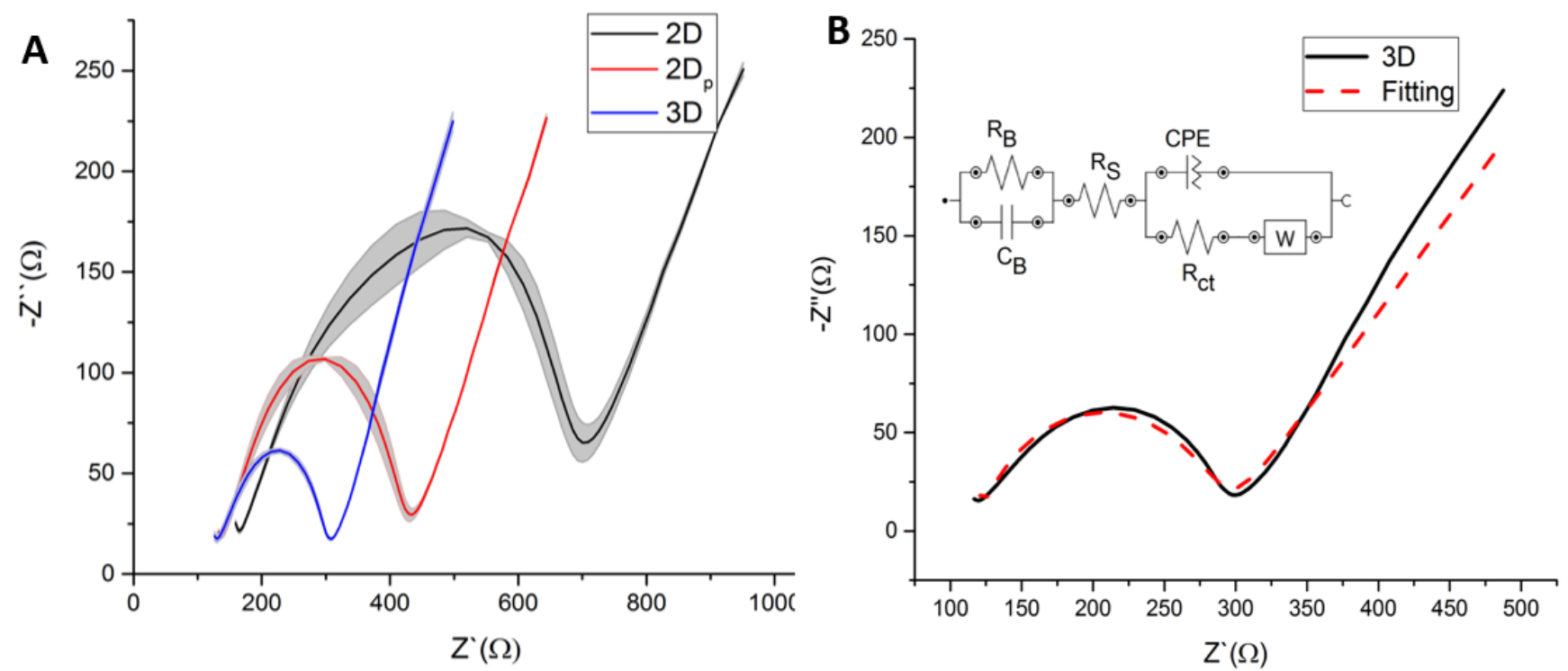

Figure 9: (A) Impedance spectra of pyrolytic carbon microelectrodes with their standard deviation ( $N=4)(B)$ Impedance spectra for 3D carbon microelectrode (design 1) with equivalent circuit fitting

The semicircle at the high frequency corresponds to the electron-transfer kinetics of the redox probe at the electrode interface, while the linear part at the lower frequency is due to the diffusion-limited electron-transfer processes [48]. The charge transfer resistance $R_{c t}$ for the 3D microelectrodes was considerably smaller than for $2 \mathrm{D}_{\mathrm{p}}$ or $2 \mathrm{D}$ microelectrodes. The decrease of the $\mathrm{R}_{\mathrm{ct}}$ is mainly due the increased surface area of 3D carbon microelectrodes which is also shown by an increase of peak current during CV. With the increase in surface area, the bulk capacitance $\left(\mathrm{C}_{\mathrm{B}}\right)$ increases and bulk resistance $\left(\mathrm{R}_{\mathrm{B}}\right)$ decreases. This is mainly due $\mathrm{sp}^{2}$ and $\mathrm{sp}^{3}$ regions in the pyrolytic carbon electrodes which acts as conducting and insulating regions respectively. Generally $\mathrm{Rs}_{\mathrm{s}}$ is the solution resistance, but for a microelectrode an additional resistance due to the electrochemical system is present. Hence a decrease in Rs for 3D carbon microelectrode. Increased surface area for a 3D carbon microelectrode increases the overall roughness and inhomogeneous electron transfer which can be seen by a decrease in $\alpha$ [21]. 
Table 2: Equivalent mean circuits values with standard deviation $(N-4)$ of different carbon microelectrode configurations

\begin{tabular}{|c|c|c|c|c|c|c|c|}
\hline & $\mathbf{R}_{\mathbf{B}}(\mathbf{\Omega})$ & $\mathbf{C}_{\mathbf{B}}(\mathbf{n F})$ & $\mathbf{R}_{\mathbf{S}}(\mathbf{\Omega})$ & $\mathbf{R}_{\mathbf{c t}}(\mathbf{\Omega})$ & $\mathbf{Q}(\boldsymbol{\mu M h o})$ & $\mathbf{W}(\mathbf{m M h o})$ & $\boldsymbol{\alpha}$ \\
\hline 2D & $34.2 \pm 3.12$ & $43.10 \pm$ & $133 \pm 1.77$ & $554.12 \pm 12.98$ & $15.41 \pm 1.87$ & $3.63 \pm 0.05$ & $0.82 \pm 0.02$ \\
& & 0.11 & & & & & \\
\hline 2D & $30.32 \pm 1.96$ & $54.40 \pm$ & $116 \pm 1.06$ & $281.3 \pm 9.21$ & $6.03 \pm 0.26$ & $4.10 \pm 0.04$ & $0.79 \pm 0.01$ \\
$\mathbf{p}$ & & 0.08 & & & & & \\
\hline 3D & $23.60 \pm 2.13$ & $66.90 \pm$ & $103 \pm 1.50$ & $161.54 \pm 5.23$ & $4.66 \pm 0.24$ & $4.55 \pm 0.08$ & $0.75 \pm 0.01$ \\
& & 0.20 & & & & & \\
\hline
\end{tabular}

3.6. Dopamine (DA) detection with square wave voltammetry

Dopamine is an important neurotransmitter in the central nervous system (CNS) [7]. Lack of dopamine releasing neurons in the CNS leads to neurodegenerative disorders such as Parkinson's disease [49]. Dopamine sensing experiments with 2D, 2Dp and 3D carbon microelectrodes were conducted. Figure 10.A shows the results obtained for dopamine detection on 3D carbon microelectrodes. Figure 10.B shows the linear increase of the peak current with the increase in DA concentrations. The SWV's for DA detection on 2D and 2 $\mathrm{D}_{\mathrm{p}}$ electrodes are given in supplementary information S5. The highly sensitive 3D carbon microelectrodes resulted in twice the peak current compared to 2D electrodes for dopamine detection. For $25 \mu \mathrm{M}$ dopamine, the 2D and 3D carbon microelectrodes resulted in currents of $33.2 \mu \mathrm{A}$ and $15.0 \mu \mathrm{A}$ respectively which corresponds to a two-fold increase of the response for DA detection using 3D carbon microelectrodes. The sensitivity of the DA detection on 3D carbon microelectrodes was $0.87 \mu \mathrm{A} \mu \mathrm{M}^{-1}$ (slope of the fitting in Figure 10.B) and $0.069 \mu \mathrm{A} \mu \mathrm{M}^{-1} \mathrm{~mm}^{-2}$ (considering WE footprint area $=12.56 \mathrm{~mm}^{2}$ ), which is higher than the reported values for other unmodified carbon microelectrodes [7], [50], [51]. 

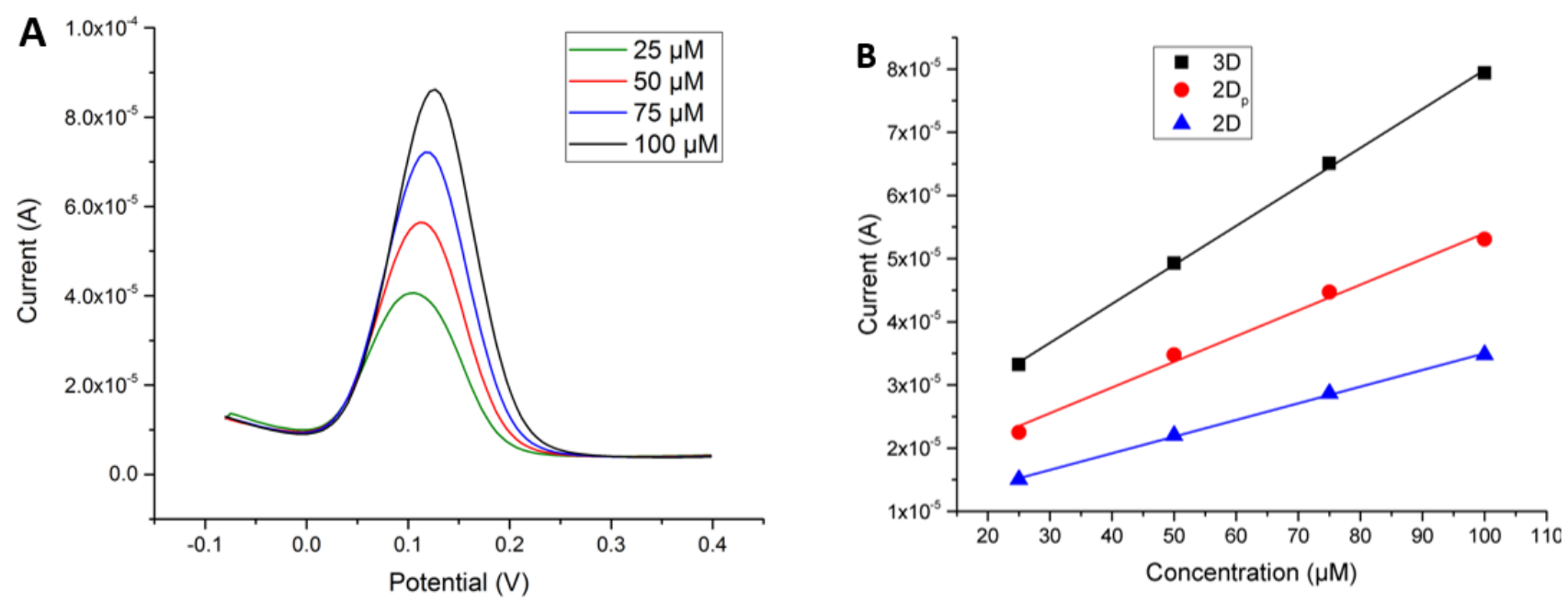

Figure 10 : (A) Square wave voltammetry for different concentration of dopamine with 3D microelectrodes (B) Different concentration of dopamine detection with 3D, 2D $\mathrm{D}$ and 2D electrode

\section{Conclusion}

Suspended multilayer SU-8 polymer templates were successfully fabricated with multiple steps of UV photolithography and pyrolysed to obtain 3D carbon microelectrodes. Five designs of 3D carbon microelectrodes were characterized for shrinkage and mechanical stability with optical microscopy, SEM, Raman and XPS. Designs with pillar pitch ( $\Phi)=$ hole pitch (c) (design 1, 2 and 4) were successfully fabricated with a very low reproducibility with a feature size of $7 \mu \mathrm{m}$. The smallest feature size of pyrolysed carbon observed on the suspended layer was $2 \mu \mathrm{m}$ (design 3 and 5) with less throughput. 3D carbon microelectrodes (design 1-5) were successfully fabricated even with a high shrinkage of $48.3 \%$, $41.0 \%$ and $48.4 \%$ for height, pillar diameter and suspended layer thickness respectively. An electrochemical chip with 3D carbon microelectrodes as working electrode, carbon as counter and gold as pseudo-reference was fabricated for electrochemical characterization. CV and EIS were used for electrochemical characterisation. CV resulted in twice the peak current for 3D microelectrode as compared to 2D electrode. Further 3D microelectrodes were characterized by CV (different scan rate and concentration) and EIS, which confirmed that 3D microelectrodes provide a higher electron transfer and lower charge transfer resistance compared to 2D electrodes due to the larger surface area. Finally 3D 
carbon microelectrodes were used to enhance DA detection, which also resulted in twice the higher current response as compared to 2D carbon electrodes.

\section{Acknowledgements}

The authors acknowledge funding by the Young Investigator Program of the Villum Foundation, project no. VKR023438.

\section{Reference}

[1] R. Martinez-Duarte, "Microfabrication technologies in dielectrophoresis applications-A review," Electrophoresis, vol. 33, no. 21, pp. 3110-3132, 2012.

[2] J. W. Long, B. Dunn, D. R. Rolison, and H. S. White, “Three-Dimensional Battery Architectures,” Chem. Rev., vol. 104, no. 10, pp. 4463-4492, Oct. 2004.

[3] A. Fendyur and M. E. Spira, “Toward on-chip, in-cell recordings from cultured cardiomyocytes by arrays of gold mushroom-shaped microelectrodes,” Front. Neuroeng., vol. 5, no. August, pp. 1-10, 2012.

[4] Y. Rui, J. Liu, Y. Wang, and C. Yang, "Parylene-based implantable Pt-black coated flexible 3-D hemispherical microelectrode arrays for improved neural interfaces,” Microsyst. Technol., vol. 17, no. 3, pp. 437-442, 2011.

[5] R. R. Kamath and M. J. Madou, “Three-dimensional carbon interdigitated electrode arrays for redox-amplification,” Anal. Chem., vol. 86, no. 6, pp. 2963-2971, 2014.

[6] F. Santoro, J. Schnitker, G. Panaitov, and A. Offenh??usser, "On chip guidance and recording of cardiomyocytes with 3D mushroom-shaped electrodes,” Nano Lett., vol. 13, no. 11, pp. 53795384, 2013. 
[7] L. Amato, A. Heiskanen, C. Caviglia, F. Shah, K. Zór, M. Skolimowski, M. Madou, L. Gammelgaard, R. Hansen, E. G. Seiz, M. Ramos, T. R. Moreno, A. Martínez-Serrano, S. S. Keller, and J. Emnéus, “Pyrolysed 3D-Carbon Scaffolds Induce Spontaneous Differentiation of Human Neural Stem Cells and Facilitate Real-Time Dopamine Detection,” Adv. Funct. Mater., vol. 24, no. 44, pp. 7042-7052, 2014.

[8] F. Greiner, S. Quednau, F. Dassinger, R. Sarwar, H. F. Schlaak, M. Guttmann, and P. Meyer, "Fabrication techniques for multiscale 3D-MEMS with vertical metal micro- and nanowire integration,” J. Micromechanics Microengineering, vol. 23, no. 2, p. 25018, 2013.

[9] S. Lee, J. Ahn, J.-M. Seo, H. Chung, and D.-I. Cho, “Electrical Characterization of 3D Au Microelectrodes for Use in Retinal Prostheses,” Sensors, vol. 15, no. 6, pp. 14345-14355, 2015.

[10] J. Voldman, M. L. Gray, M. Toner, and M. A. Schmidt, “A Microfabrication-Based Dynamic Array Cytometer parallel luminescent single-cell assays that can sort popu-,” vol. 74, no. 16, pp. 3984-3990, 2016.

[11] V. Piotter, T. Benzler, T. Gietzelt, R. Ruprecht, and J. Hauelt, "Micro Powder Injection Molding,” Adv. Eng. Mater., vol. 2, no. 10, pp. 639-642, 2000.

[12] A. C. Siegel, D. A. Bruzewicz, D. B. Weibel, and G. M. Whitesides, "Microsolidics: Fabrication of three-dimensional metallic microstructures in poly(dimethylsiloxane),” Adv. Mater., vol. 19, no. 5, pp. 727-733, 2007.

[13] S. Kim, J. Park, K. Kang, C.-O. Park, and I. Park, "Direct metal micropatterning on needle-type structures towards bioimpedance and chemical sensing applications,” J. Micromechanics Microengineering, vol. 25, no. 1, p. 15002, 2015.

[14] S.-Y. Wu, C. Yang, W. Hsu, and L. Lin, “3D-printed microelectronics for integrated circuitry and passive wireless sensors,” Microsystems Nanoeng., vol. 1, no. April, p. 15013, 2015.

[15] J. Xu, D. Wu, J. Y. Ip, K. Midorikawa, and K. Sugioka, "Vertical sidewall electrodes monolithically integrated into 3D glass microfluidic chips using water-assisted femtosecondlaser fabrication for in situ control of electrotaxis,” RSC Adv., vol. 5, no. 31, pp. 24072-24080, 2015. 
[16] P. Paiè, F. Bragheri, R. M. Vazquez, and R. Osellame, "Straightforward 3D hydrodynamic focusing in femtosecond laser fabricated microfluidic channels.," Lab Chip, vol. 14, no. 11, pp. 1826-33, 2014.

[17] A. Hart and H. Taylor, "2D and 3D growth of carbon nanotubes on substrates, from nanometre to millimetre scales,” Int. J. Nanomanuf., vol. X, no. Y, pp. 1-9, 2007.

[18] S. Rajaraman, S.-O. Choi, R. H. Shafer, J. D. Ross, J. Vukasinovic, Y. Choi, S. P. DeWeerth, A. Glezer, and M. G. Allen, "Microfabrication technologies for a coupled three-dimensional microelectrode, microfluidic array,” J. Micromechanics Microengineering, vol. 17, no. 1, pp. 163-171, 2006.

[19] J.-W. Choi, S. Rosset, M. Niklaus, J. R. Adleman, H. Shea, and D. Psaltis, “3-Dimensional Electrode Patterning Within a Microfluidic Channel Using Metal Ion Implantation.,” Lab Chip, vol. 10, no. 6, pp. 783-788, 2010.

[20] C. Wang and M. Madou, "From MEMS to NEMS with carbon,” Biosens. Bioelectron., vol. 20, no. 10 SPEC. ISS., pp. 2181-2187, 2005.

[21] R. L. McCreery, “Advanced carbon electrode materials for molecular electrochemistry,” Chem. Rev., vol. 108, no. 7, pp. 2646-2687, 2008.

[22] M. Beidaghi and C. Wang, "Micro-supercapacitors based on three dimensional interdigital polypyrrole/C-MEMS electrodes,” Electrochim. Acta, vol. 56, no. 25, pp. 9508-9514, 2011.

[23] R. Martinez-Duarte, R. Gorkin, K. Abi-Samra, and M. J. Madou, "The integration of 3D carbon dielectrophoresis on a rotating platform,” TRANSDUCERS 2009 - 15th Int. Conf. Solid-State Sensors, Actuators Microsystems, pp. 2147-2150, 2009.

[24] R. Martinez-Duarte, "SU-8 Photolithography as a Toolbox for Carbon MEMS,” Micromachines, vol. 5, no. 3, pp. 766-782, 2014.

[25] A. del Campo and C. Greiner, "SU-8: a photoresist for high-aspect-ratio and 3D submicron lithography,” J. Micromechanics Microengineering, vol. 17, no. 6, pp. R81-R95, 2007.

[26] V. J. Cadarso, K. Pfeiffer, U. Ostrzinski, J. B. Bureau, G. a Racine, A. Voigt, G. Gruetzner, and 
J. Brugger, "Direct writing laser of high aspect ratio epoxy microstructures," J. Micromechanics Microengineering, vol. 21, no. 1, p. 17003, 2011.

[27] K. Ohlinger, Y. Lin, Z. Poole, and K. P. Chen, "Undistorted 3D microstructures in SU8 formed through two-photon polymerization,” AIP Adv., vol. 1, no. 3, 2011.

[28] Y. Lim, J.-I. Heo, and H. Shin, "Fabrication and application of a stacked carbon electrode set including a suspended mesh made of nanowires and a substrate-bound planar electrode toward for an electrochemical/biosensor platform," Sensors Actuators B Chem., vol. 192, no. 2014, pp. 796-803, 2014.

[29] F. Ceyssens and R. Puers, "Creating multi-layered structures with freestanding parts in SU-8," $J$. Micromechanics Microengineering, vol. 16, no. 6, pp. S19-S23, 2006.

[30] J. Melai, V. M. Blanco Carballo, C. Salm, and J. Schmitz, "Suspended membranes, cantilevers and beams using SU-8 foils,” Microelectron. Eng., vol. 87, no. 5-8, pp. 1274-1277, 2010.

[31] A. Rammohan, P. K. Dwivedi, R. Martinez-Duarte, H. Katepalli, M. J. Madou, and A. Sharma, "One-step maskless grayscale lithography for the fabrication of 3-dimensional structures in SU8,” Sensors Actuators, B Chem., vol. 153, no. 1, pp. 125-134, 2011.

[32] S.Hemanth, C.Caviglia, L. Amato, T. A. Anhøj, A.Heiskanen, J. Emnéus, and S. S. Keller, “Pyrolytic 3D Carbon Microelectrodes for Electrochemistry,” in ECS Transactions, 2016, vol. 72, no. 1, pp. 117-124.

[33] L. Amato, S. S. Keller, A. Heiskanen, M. Dimaki, J. Emnéus, A. Boisen, and M. Tenje, "Fabrication of high-aspect ratio SU-8 micropillar arrays," Microelectron. Eng., vol. 98, pp. 483-487, 2012.

[34] L. Amato, A. Heiskanen, R. Hansen, L. Gammelgaard, T. Rindzevicius, M. Tenje, J. Emnéus, and S. S. Keller, "Dense high-aspect ratio 3D carbon pillars on interdigitated microelectrode arrays," Carbon N. Y., vol. 94, pp. 792-803, 2015.

[35] R. Martinez-duarte, P. Renaud, and M. J. Madou, "A novel approach to dielectrophoresis using carbon electrodes," pp. 2385-2392, 2011. 
[36] L. Amato, A. Heiskanen, R. Hansen, L. Gammelgaard, T. Rindzevicius, M. Tenje, J. Emnéus, and S. S. Keller, “Dense high-aspect ratio 3D carbon pillars on interdigitated microelectrode arrays,” Carbon N. Y., vol. 94, pp. 792-803, Nov. 2015.

[37] E. C. S. Transactions and T. E. Society, “Shrinkage Analysis of Carbon Micro Structures Derived from SU-8 Photoresist R. Natu, M. Islam and R. Martinez-Duarte Department of Mechanical Engineering, Clemson University, Clemson, South Carolina 29634, USA,” vol. 72, no. 1, pp. 27-33, 2016.

[38] K. S. Chen and R. Z. Yeh, “Pyrolysis kinetics of epoxy resin in a nitrogen atmosphere,” J. Hazard. Mater., vol. 49, no. 2-3, pp. 105-113, 1996.

[39] C.-C. M. Ma, C.-Y. Chen, H.-C. Kuan, and W.-C. Chang, "Processability, Thermal, Mechanical, and Morphological Properties of Novolac Type-Epoxy Resin-Based Carbon-Carbon Composite,” J. Compos. Mater., vol. 38, no. 4, pp. 311-322, 2004.

[40] P. K. Chu and L. Li, “Characterization of amorphous and nanocrystalline carbon films,” Mater. Chem. Phys., vol. 96, no. 2-3, pp. 253-277, 2006.

[41] T. Takahagi and a. Ishitani, “Xps Study on the Surface Structure of,” Carbon N. Y., vol. 26 , no. 3, pp. 389-396, 1988.

[42] R. Kostecki, B. Schnyder, D. Alliata, X. Song, K. Kinoshita, and R. Kötz, "Surface studies of carbon films from pyrolyzed photoresist,” Thin Solid Films, vol. 396, pp. 36-43, 2001.

[43] A. C. Ferrari, "Raman spectroscopy of graphene and graphite : Disorder, electron - phonon coupling , doping and nonadiabatic effects,” solid state Commun., vol. 143, pp. 47-57, 2007.

[44] P. Zanello, Inorganic Electrochemistry. Cambridge: Royal Society of Chemistry, 2003.

[45] K. K. Mistry, S. Deepthy, C. R. Chaudhuri, and H. Saha, "Electrochemical characterization of some commercial screen-printed electrodes in different redox substrates,” Curr. Sci., vol. 109, no. 8, pp. 1427-1436, 2015.

[46] P. J. Lamas-ardisana and A. Mart, "Electrochemical characterization of screen- printed and conventional carbon paste electrodes and conventional carbon paste electrodes,” Electrochim. 
Acta, no. April, 2008.

[47] H. Luo, Z. Shi, N. Li, Z. Gu, and Q. Zhuang, "Investigation of the Electrochemical and Electrocatalytic Behavior of Single-Wall Carbon Nanotube Film on a Glassy Carbon Electrode,” Anal. Chem., vol. 73, no. 5, pp. 915-920, 2001.

[48] A. J. Bard and Faulkner, Electrochemical Methods, vol. 30, no. 1. 2000.

[49] M. Politis and O. Lindvall, "Clinical application of stem cell therapy in Parkinson’s disease," BMC Med., vol. 10, no. 1, p. 1, 2012.

[50] R. S. Pai, K. M. Walsh, M. M. Crain, T. J. Roussel, D. J. Jackson, R. P. Baldwin, R. S. Keynton, and J. F. Naber, "Fully Integrated Three-Dimensional Electrodes for Electrochemical Detection in Microchips : Fabrication , Characterization, and Applications," Anal. Chem., vol. 81, no. 12, pp. 4762-4769, 2009.

[51] D. J. Fischer, W. R. Vandaveer, R. J. Grigsby, and S. M. Lunte, "Pyrolyzed Photoresist Carbon Electrodes for Microchip Electrophoresis with Dual-Electrode Amperometric Detection," Electroanalysis, pp. 1153-1159, 2005. 